\title{
Infecciones de transmisión sexual en mujeres en situación de privación de la libertad de un establecimiento penitenciario en Mérida, Venezuela.
}

\author{
Jorge Cañarte Alcivar ${ }^{1}$, Melina Moreano Zambrano ${ }^{1}$, Mónica Guerrero Madroñero ${ }^{3}$, \\ Miguel Giler Zambrano ${ }^{4}$, Diana Callejas Monsalve ${ }^{1,5}$, Mike Telémaco Contreras \\ Colmenares ${ }^{6}$ y Luis Eduardo Télles Gil ${ }^{6}$ \\ ${ }^{1}$ Facultad de Ciencias de la Salud, Universidad Técnica de Manabí. Portoviejo, Manabí. \\ Ecuador. \\ ${ }^{2}$ Hospital del Instituto Ecuatoriano del Seguro Social (IESS), Quito-sur, Quito, \\ Pichincha. Ecuador. \\ ${ }^{3}$ Centro Médico StemMedic, Manta, Manabí. Ecuador. \\ ${ }^{4}$ Universidad de Guayaquil, Guayas. Ecuador. \\ ${ }^{5}$ Universidad del Zulia, Facultad de Medicina, División de Estudios de Post Grado, \\ Maracaibo. Venezuela. \\ ${ }^{6}$ Universidad de Los Andes, Facultad de Medicina, Departamento de Microbiología, \\ Mérida. Venezuela. \\ Palabras clave: reclusas; infecciones de transmisión sexual; prevalencia; factores de \\ riesǵo; estudio caso control.
}

Resumen. Las infecciones de transmisión sexual (ITS) y conductas sexuales de riesgo, son prevalentes en mujeres encarceladas. Este estudio mostró que las ITS fueron más frecuentes en mujeres reclusas $(66,6 \%)$ que en mujeres en libertad ( $\mathrm{p} \leq 0,001)$. Solo el grupo de encarceladas presentó combinaciones de ITS (39\%) $(\mathrm{p} \leq 0,019)$, siendo significativas las infecciones por VPH ( $\leq$ $0,007)$ y Chlamydia trachomatis $(\mathrm{p} \leq 0,003)$ con otros agentes causales. VPH y Chlamydia trachomatis fueron más frecuentes en reclusas $(35,7 \%)$, mientras que las mujeres libres presentaron $9,5 \%(\mathrm{p} \leq 0,004)$ y $7,1 \%$ respectivamente $(\mathrm{p} \leq 0,001)$. Las reclusas presentaron combinaciones de diferentes genotipos de VPH $(\mathrm{p} \leq 0,011)$. Las infecciones por Treponema pallidum ocurrieron en 7,1 $\%$ en reclusas y estuvieron ausentes en las libres. El virus de la hepatitis B, estuvo presente en un $9,5 \%$ de reclusas y ausente en mujeres libres $(p \leq 0,040)$. Los marcadores para hepatitis $\mathrm{C}$ y el virus de la inmunodeficiencia humana (VIH) fueron negativos en ambos grupos; los virus herpes simplex tipo 1 y 2 (VHS) se encontraron en $9,5 \%$ de las reclusas y en $7,1 \%$ de mujeres libres. El consumo

Autor de correspondencia: Jorge Cañarte-Alcívar. Facultad de Ciencias de la Salud, Universidad Técnica de Manabí. Portoviejo, Manabí. Ecuador. Correo electrónico: jcanarte@utm.edu.ec 
de tabaco, alcohol y el uso de otras drogas, mostró una frecuencia de 100\%, $89,3 \%$ y $78,6 \%$ respectivamente en mujeres reclusas y un $40 \%, 30 \%$ y $10 \%$ en las libres $(\mathrm{p} \leq 0,001)$. El número de parejas sexuales en relación a la presencia de ITS entre ambos grupos, mostró significancia para un número de dos o más parejas $(\mathrm{p}<0,006)$. Se observó una elevada prevalencia de ITS únicas o mixtas en mujeres reclusas, así como factores asociados a conductas sexuales de riesgoo.

\title{
Sexually transmitted infections in inmates in Merida Venezuela.
}

\section{Invest Clin 2020; 61 (3): 227-241}

Key words: inmates; sexually transmitted infections; prevalence; risk factors; case control study.

\begin{abstract}
Sexually transmitted infections (STIs) and sexual risk behaviors are prevalent in incarcerated women. This study showed that STIs were more frequent in female prisoners (66.6\%) than in women in freedom ( $\mathrm{p} \leq 0.001)$. Only the group of incarcerated women presented a combination of STIs (39\%) $(\mathrm{p} \leq 0.019)$, being significant the combination of HPV $(\mathrm{p} \leq 0.007)$ and Chlamydia trachomatis $(\mathrm{p} \leq 0.003)$ with other causative agents. HPV and Chlamydia trachomatis were more frequent in female prisoners (35.7\%), while in non-incarcerated women occurred in $9.5 \%(\mathrm{p} \leq 0.004)$ and $7.1 \%$, respectively $(\mathrm{p} \leq 0.001)$. The inmates presented a combination of different HPV genotypes $(\mathrm{p} \leq 0.011)$. Treponema pallidum presented in $7.1 \%$ of prisoners and it was negative in free ones. Hepatitis B virus was present in $9.5 \%$ of inmates and negative in free women $(\mathrm{p} \leq 0.040)$. Markers for hepatitis $\mathrm{C}$, and human immunodeficiency virus (HIV) were negative in both groups; herpes simplex virus types 1 and 2 (HSV) were found in $9.5 \%$ of the inmates and in $7.1 \%$ of free women. The consumption of tobaceo, alcohol and the use of other drugs showed a frequency of $100 \%, 89.3 \%$ and $78.6 \%$, respectively, of female prisoners and of $40 \%, 30 \%$ and $10 \%$ in free women $(\mathrm{p} \leq 0.001)$. The number of sexual partners in relation to the presence of STIs between both groups showed significance for a number of two or more partners ( $\mathrm{p}<0.006)$. A high prevalence of single or mixed STIs was observed in female prisoners, as well as factors associated with risky sexual behaviors.
\end{abstract}

Recibido: 17-03-2020 Aceptado: 15-09-2020

\section{INTRODUCCIÓN}

Las Infecciones de Transmisión Sexual (ITS) son un importante problema de salud pública que afecta la salud sexual y reproductiva en el mundo, figurando como una de las cinco principales causas de atención médica en el adulto (1,2). Se ha contabilizado que más de 1 millón de personas contraen diariamente una ITS y se estima que anualmente unos 357 millones de personas adquieren alguna de las siguientes enfermedades: clamidiasis (131 millones), blenorragia (78 millones), sífilis (5,6 millones) y 
tricomoniasis (143 millones). En este mismo sentido, se ha documentado que el número de personas con infección genital por el virus herpes simple (VHS) supera los 500 millones y que existen más de 290 millones de mujeres infectadas con el virus papiloma humano (VPH) $(3,4)$.

Dos de las ITS comúnmente reportadas que son prevalentes entre adolescentes y adultos jóvenes en la población general son las provocadas por Chlamydia trachomatis y Neisseria gonorrhoeae (5).

La bacteria intracelular Chlamydia trachomatis es causante de una de las ITS más frecuentes que padecen las mujeres del mundo occidental. Las estadísticas en salud femenina han proyectado una ocurrencia alrededor de 2,9 millones de nuevas infecciones por este agente bacteriano en los Estados Unidos cada año (6). La importancia del conocimiento de esta infección es estar en capacidad de medir el riesgo de complicaciones agudas y a largo plazo, tales como la enfermedad inflamatoria pélvica, embarazo ectópico, dolor pélvico crónico e infertilidad como problemas de la salud reproductiva en la mujer. Así mismo, se ha demostrado que la transmisión de este agente aumenta el riesgo de adquirir la infección por el virus de la inmunodeficiencia humana (VIH) hasta en 3 veces más (6-8).

Otra de las bacterias que se puede transmitir mediante vía sexual es el Treponema pallidum responsable de la sífilis, enfermedad crónica que continúa siendo un problema de salud pública alarmante en todo el mundo. Se estima que aproximadamente existen $36 \mathrm{mi}$ llones de casos prevalentes en todo el mundo y más de 12 millones de casos de incidentes anualmente. Esta enfermedad se ha convertido en una de las cinco enfermedades infecciosas más reportada, es la ITS más frecuente en Brasil. La estimación de nuevas infecciones en la población adulta son de 937.000,00 casos cada año, con una prevalencia de 2,6\%, que puede variar entre $1,0 \%$ a $4,4 \%$ (9).

Los agentes virales como el VIH y el virus de la hepatitis B (VHB) pueden cursar con periodos asintomáticos durante años, pero generan daños crónicos y complicaciones de por vida en la salud de la mujer. Recientemente, la infección por el virus del herpes del tipo 2 (VHS2) ha recibido una atención especial pues se ha demostrado que puede aumentar el riesgo de infección por VIH hasta tres veces, acelerando su progresión (10).

Todas estas entidades bacterianas y virales que pueden generar enfermedad en el tracto genitourinario y amplificar el daño hacia el sistema orgánico, tienden a comportarse de forma diferente según sea la población portadora y su correspondiente comportamiento epidemiológíco (8). Es así como diversas instituciones como el Centro para el Control y la Prevención de Enfermedades (CDC) y la Organización Panamericana de la Salud (OPS) han señalado, con preocupación, la incidencia desproporcionada de ITS en mujeres reclusas o privadas de libertad en comparación con la población femenina general (8). En efecto, se ha constatado que la circulación de agentes productores de ITS representa una mayor prevalencia en este grupo, incluso comparadas con los hombres encarcelados. Estudios previos han informado un aumento en las conductas sexuales provocada por la privación de libertad. La alta prevalencia de estas infecciones puede verse influenciada por factores que preceden al mismo encarcelamiento; entre ellos, el bajo nivel socioeconómico, comportamientos sexuales de alto riesǵo, acceso limitado a los servicios de salud y cuidado, y el uso de drogas inyectables (10). De igual manera, se ha determinado que los hábitos psicobiológicos como el consumo elevado de bebidas alcohólicas están estrechamente relacionados con una mayor prevalencia de ITS en las mujeres encarceladas (7).

Se ha demostrado que existen varios factores de riesgo que están correlacionados con el aumento de ITS en la población femenina en general, como el inicio de la actividad sexual a temprana edad, tener múltiples compañeros sexuales y/o pareja promiscua, 
el uso inconsistente del condón o padecimiento previo de alguna ITS, también se ha señalado con preocupación la incidencia de estas características en la población encarcelada. Así mismo, los antecedentes de las conductas sexuales de alto riesgó, incluido el comercio sexual, gran número de parejas masculinas, así como los abusos sexuales previos, aumentan en las mujeres encarceladas el riesgo de padecer ITS en su modalidad única o presentación múltiple o mixta (7).

Del mismo modo, el uso de drogas, aunada a la práctica sexual sin protección, y haber tenido múltiples parejas sexuales en las poblaciones penitenciarias, representa un alto riesgo de adquirir por ejemplo sífilis y el virus de la hepatitis C (VHC) (9). Otro factor de riesgo importante que enfrentan las reclusas es el hacinamiento y tener que compartir objetos contaminados (10).

Los datos sobre la incidencia de las distintas ITS en población de mujeres reclusas varían según el desarrollo, los programas de salud pública y prevención que hay en cada país, así como el comportamiento de los grupos de edad que hay en cada correccional. Así, se ha registrado tasas de infección por Chlamydia trachomatis del 7\%, y Neisseria gonorrhoeae del 3\% entre las mujeres que ingresaron a 38 instituciones correccionales para adultos. Estas tasas han ido en aumento, estimándose prevalencias anteriores de C. trachomatis del 1,8\% y de $N$. gonorrhoea del $0,2 \%$ entre las mujeres entre 18 y 40 años en los Estados Unidos. En entornos correccionales en los EEUU, se demostró que las tasas de prevalencia de Chlamydia trachomatis eran muy elevadas, hasta del 21\% entre las mujeres menores de 25 años $(7,8)$.

Numerosos estudios de detección y varias revisiones en los Estados Unidos revelan que las mujeres, específicamente las adolescentes en centros juveniles y las mujeres en centros correceionales para adultos, tienen más probabilidades de tener una ITS que los hombres; las reclusas adultas tienen las tasas de positividad más altas para la sífilis, mientras que las adolescentes en detención juvenil tienen las tasas más altas de gonorrea y Chlamydia. Las tasas de sífilis tienden a ser más altas para los adultos que para los jóvenes y más altas en las cárceles. La Chlamydia es más frecuente entre los jóvenes varones y mujeres que entre los reclusos adultos, mientras que la gonorrea es más frecuente entre adolescentes en centros juveniles que las mujeres en correccionales (11).

Datos sobre la prevalencia y los factores de riesgo para VIH, VHB, sífilis y VHS2 entre la población presa en América Latina es escasa; la información sobre la prevalencia de estas enfermedades y sus factores de riesgo correspondientes en las cárceles es de crucial importancia, en particular en países con recursos limitados para priorizar y planificar medidas preventivas específicas e intervenciones sanitarias eficientes (10).

El objetivo de este estudio fue evaluar la prevalencia y los factores de riesgo asociados con las infecciones de transmisión sexual en mujeres recluidas en el anexo femenino del centro penitenciario de la región andina del estado Mérida, Venezuela y comparar con mujeres de la comunidad para establecer significancia estadística mediante un modelo de estudio analítico tipo caso-control.

\section{PACIENTES Y MÉTODOS}

\section{Población en estudio}

Se realizó un estudio analítico de tipo caso-control en mujeres reclusas en el anexo femenino del centro penitenciario de la Región Andina del estado Mérida, Venezuela. Se estudiaron 84 mujeres, cuyas muestras se recolectaron desde enero a julio 2018; de las 84 mujeres, 42 fueron reclusas correspondientes al grupo de estudio y 42 fueron mujeres de la comunidad en condición de libertad quienes conformaron el grupo control. Este último grupo acudió al control anual en la consulta de ginecología del Instituto Autónomo Hospital Universitario de Los Andes (IAHULA). En ambos grupos se aplicó un instrumento diseñado para la recolección de datos, un cuestionario estándar donde se 
registraron datos personales, epidemiológicos, socioeconómicos, hábitos psicosociales, así como datos clínicos y ginecológicos de interés. Cada mujer recibió una explicación relacionada al estudio; las que decidieron participar recibieron un consentimiento informado y diseñado, para el estudio según los estándares establecidos en la declaración de Helsinki, el cual fue firmado. El protocolo de trabajo fue evaluado y aprobado por el Comité de Bioética del Instituto de Biomedicina, Ministerio del Poder Popular para la Salud, y por el Consejo de Facultad de Medicina, Universidad de Los Andes, Mérida, Venezuela.

\section{Ensayos inmunoserológicos}

La toma de muestra sanguínea se hizo mediante venopunción siguiendo las normas de bioseguridad para para la obtención del suero sanguíneo. Luego de su obtención, el suero se congeló a $-20^{\circ} \mathrm{C}$ para hacer el estudio serológico. Las pruebas de detección de las ITS diferentes a la infección por VPH, evaluadas en la presente investigación, fueron realizadas por personal especializado del Laboratorio de Microbiología y Salud Pública, ULE-ULA Mérida. Para identificar la infección por el Virus del Herpes Simplex, Treponema pallidum y Chlamydia trachomatis se realizó la detección de anticuerpos específicos IgM e IgG dirigidos contra estos patógenos mediante (Elisas That Performs, DRG Products, DRG Alemania). Para la detección del VIH1 y 2 se usó un ELISA indirecto (UMELISA HIV 1+2 RECOMBINANT, SUMA), para anticuerpos específicos al VIH en muestras de suero. Esta prueba utiliza como antígenos de captura las proteínas representativas de la envoltura y el cuerpo viral del VIH-1, gp120, p41 y p24, y la proteína representativa de la envoltura viral del VIH-2, gp36. Iǵualmente, se utilizó un ELISA indirecto (UMELISA VHC, SUMA) para la detección del VHC buscando anticuerpos específicos. Esta prueba utiliza, como antígenos de captura, péptidos sintéticos correspondientes a las regiones del núcleo, reǵiones no estructurales NS4 y NS5 y una proteína recombinante de la región NS3 del VHC. En cuanto al diagnóstico del VHB, se aplicaron dos ensayos inmunoenzimáticos: el primero fue para la detección de anticuerpos anti-antígenos de superficie del virus de hepatitis B (VHBsAg) por micro ensayo inmunoenzimático (MICRO ELISA). La detección de VHBsAg fue realizada aplicando el ensayo indirecto (UMELISA HBsAg, SUMA); esta prueba se realiza tomando como base la reacción inmunoenzimática en el cual del antígeno de superficie de la hepatitis $\mathrm{B}$ reacciona con anticuerpos monoclonales contra el mismo. El segundo ensayo aplicado estuvo dirigido a la detección de anticuerpos antiantígeno del núcleo del virus de la hepatitis B (VHBc) por micro ensayo inmunoenzimático (MICRO ELISA). La detección de VHBc fue realizada aplicando el ensayo indirecto heterogéneo (UMELISA ANTI VHBc, SUMA); esta prueba utiliza como antígeno de captura, el antígeno núcleo del virus de la hepatitis $\mathrm{B}$, obtenido por vía recombinante.

\section{Detección del VPH mediante amplificación del segmento génico e6/e7}

A todas las mujeres participantes (Grupo de Estudio y Grupo Control) les fue realizado un examen ginecológico y toma de muestras por parte de un especialista. Las muestras fueron recolectadas con un cepillo tratando de localizar el canal endocervical y el área del exocervix para extraer la mayor cantidad de células y proceder al diaǵnóstico molecular y la tipificación del VPH. Los cepillados se preservaron en tubos Eppendorf con capacidad de $1,5 \mathrm{~mL}$ y se almacenaron a $-20^{\circ} \mathrm{C}$ hasta el procesamiento. Para el aislamiento del $\mathrm{ADN}$ a partir de las diferentes muestras cervicales obtenidas, se utilizó el estuche comercial de extracción QLAamp DNA Mini Kit (QLAGEN®), de acuerdo con las instrucciones del laboratorio fabricante. La concentración del ADN extraído se determinó por espectrofotometría, a $260 \mathrm{~nm}$ utilizando el fotómetro UV1101/1101T (Biotech, Cambridge, UK). Luegoo se procedió a 
la detección y genotipificación del VPH en las muestras de ADN aisladas mediante, reacción de la cadena de la polimerasa (RCP). Con la RCP de detección se amplificó la región génica viral e6/e7 utilizando el sistema de iniciadores GP-E6-3F/5B/6B: GP-E6-3F (secuencia 5'-3': DNA-GGG WGK KAC TAG AAT CGG T); GP-E6-5B (secuencia 5'-3': DNA- CTG AGC TGT CAR NTA ATT GCT CA) y GP-E6-6B (secuencia 5'-3': DNA- TCG TCT GAG TYG YCT AAT TGC TC), los cuales generan un amplímero con un rango entre 602 pb y 666 pb (12). Las reacciones se llevaron a cabo con un volumen final de $20 \mu \mathrm{L}$, conteniendo $100 \mathrm{ng}$ de $\mathrm{ADN}$ genómico total, 10 $\mu \mathrm{L}$ de HotStarTaq ${ }^{\circledR}$ Master Mix 2X y $400 \mathrm{nM}$ de cada oliǵonucleótido. Se utilizó el control positivo comercial HPV-C001 (Maxim Biotech, Inc.) y como control interno de la reacción se amplificó simultáneamente el gen de la $\beta$-globina humana con un producto de $248 \mathrm{pb}$. El perfil térmico se programó: desnaturalización a $94^{\circ} \mathrm{C}$ por 15 minutos, de 40 ciclos: desnaturalización $94^{\circ} \mathrm{C}$ por $1 \mathrm{mi}-$ nuto, apareamiento o hibridación a $55^{\circ} \mathrm{C}$ por 1 minuto y extensión a $72^{\circ} \mathrm{C}$ por 1 minuto; y un paso de extensión final a $72^{\circ} \mathrm{C}$ por 10 minutos (12).

\section{Genotipificación del VPH}

Las muestras que resultaron positivas para la detección del VPH se analizaron en una seǵunda reacción para genotipificar mediante una metodología en formato de ensayo múltiple. Se utilizaron iniciadores específicos (Tabla I). Las reacciones se prepararon en dos tubos; en el primero, se identificaron los genotipos de VPH AR VPH16 y 18 y, en el segundo, los VPH AR VPH33 y VPH BR de bajo riesgo VPH6/11 (12). En la mezcla de reacción se utilizaron $10 \mu \mathrm{L}$ de HotStarTaq ${ }^{\circledR}$ Master Mix 2X y 400 nM de cada oligonucleótido; como ADN blanco se tomaron 2 $\mu l$ a partir de la dilución $1 / 10$ del producto de la PCR GP-e6/e7, en un volumen final de $20 \mu \mathrm{L}$. Se utilizaron los controles positivos VPH-C001 para VPH16/18; VPH-4009 para VPH33 y VPH-4012 para VPH6/11 (Maxim Biotech, Inc.). Perfil térmico: desnaturalización a $94^{\circ} \mathrm{C}$ por 15 minutos; 35 ciclos: desnaturalización $94^{\circ} \mathrm{C}$ por 30 segundos, apareamiento o hibridación a $56^{\circ} \mathrm{C}$ por 30 segundos y extensión a $72^{\circ} \mathrm{C}$ por 45 segundos; y un paso de extensión final a $72^{\circ} \mathrm{C}$ por 4 minutos (12). Todas las amplificaciones anteriormente descritas, se procesaron en un termociclador modelo ABI 2400 (Applied Biosystems). Los productos de las reacciones se sometieron a electroforesis en gel de agarosa al $1,20 \%$ con $10 \mu \mathrm{L}$ de bromuro de etidio/100 $\mathrm{ml}$ de agar, y posterior visualización con iluminación UV. En la corrida electroforética se incluyó un marcador de peso molecular de $1.000 \mathrm{pb}$, escalera de $100 \mathrm{pb}$

TABLA I

SECUENCIAS UTILIZADAS PARA LA GENOTIPIFICACIÓN DEL VIRUS PAPILOMA HUMANO ENCONTRADO EN LAS MUESTRAS DE GUELLO UTERINO DE MUJERES RECLUSAS Y LIBRES.

\begin{tabular}{cccc}
\hline \multicolumn{2}{c}{ VPH de Alto Riesgo Oneogénico } \\
\hline $\begin{array}{c}\text { Genotipo } \\
\text { de VPH }\end{array}$ & $\begin{array}{c}\text { Iniciador } \\
\text { Fwd })\end{array}$ & $\begin{array}{c}\text { Reverso } \\
(\text { Rev })\end{array}$ & $\begin{array}{c}\text { Tamaño } \\
\text { amplicón } \\
(\mathrm{pb})\end{array}$ \\
\hline VPH16 & CACAGTTATGCACAGAGCTGC & CATATATTCATGCAATGTAGGTGTA & 457 \\
VPH18 & GACTTCACTGCAAGACATAGA & GTTGTGAAATCGTCGTTTTTCA & 322 \\
VPH33 & ACTATACACAACATTGAACTA & GTTTTTACACGTCACAGTGCA & 398 \\
\hline
\end{tabular}

VPH de Bajo Riesgoo Oncogénico

VPH 6/11 TGCAAGAATGCACTGACGAC TGCATGTTGTCGAGCAGTGT 334

Fuente: (12). 
(100 bp DNA Ladder, Invitrogen) y buffer 10X blue juiceTM gel loading buffer (Invitrogen) para verificar el tamaño de las bandas obtenidas.

\section{Análisis estadístico}

Los datos obtenidos se vaciaron en el programa estadístico SPSS versión 22 para Windows. Para el análisis estadístico descriptivo de los resultados, se utilizó la distribución de frecuencia de las infeceiones por VPH de alto y bajo riesgo (infección única y mixta) y de las otras infecciones de transmisión sexual de origen viral y bacteriano diferentes de VPH, asociándolas en escalas cualitativas de los dos grupos estudiados en este modelo. El análisis estadístico inferencial y la definición de asociaciones significativas se realizó mediante la prueba de Chi-cuadrado, tomando como significativos valores menores de $\mathrm{p}<0,05$.

\section{RESULTADOS}

El promedio de edad de las mujeres reclusas fue de 31,9 \pm 9,4 años con un rango de edades entre los 18 y 55 años, y de las mujeres libres fue de 35,7 $\pm 9,4$ años con un rango de edades entre 19 y 56 años. Del total de mujeres reclusas que resultaron positivas para la presencia de ITS, 64,2\% fueron $<35$ años de edad, y de estas $94,4 \%$ correspondieron a mujeres jóvenes < de 30 años de edad.

En la Tabla II se puede observar que, en el 66,6\% de las mujeres reclusas se detectó la presencia de ITS, mientras que en las mujeres en condición de libertad estas infecciones se encontraron en un $23,8 \%$, diferencia que resultó ser estadísticamente significativa $(\mathrm{p} \leq 0,001)$.

En relación a las infecciones únicas, 17 mujeres recluidas en el anexo femenino presentaron esta condición (61\%), mientras que las 10 mujeres libres en las que se identificó la presencia de ITS presentaron este hallazgo (100\%). Solo las mujeres reclusas en un 39\% $(\mathrm{N}=11)$ presentaron coinfección por varios tipos de ITS. Ambas condiciones de presentación de las ITS mostraron significancia estadística en relación a la condición de privación de la libertad $(\mathrm{p} \leq 0,019)$ (Tabla III).

La infección por VPH fue una de las ITS encontrada con mayor frecuencia en las mu-

TABLA II

FRECUENCIA DE INFEGCIONES DE TRANSMISIÓN SEXUAL EN MUJERES RECLUSAS Y LIBRES. MÉRIDA, VENEZUELA. 2018.

\begin{tabular}{|c|c|c|c|c|c|c|}
\hline & \multicolumn{6}{|c|}{ Presencia de infección de transmisión sexual (ITS) } \\
\hline & \multicolumn{2}{|c|}{ Sí } & \multicolumn{2}{|c|}{ No } & \multicolumn{2}{|c|}{ Total } \\
\hline & $\mathrm{N}$ & $\%$ & $\mathrm{~N}$ & $\%$ & $\mathrm{~N}$ & $\%$ \\
\hline Reclusa & 28 & 66,6 & 14 & 33,4 & 42 & 50 \\
\hline Libre & 10 & 23,8 & 32 & 76.2 & 42 & 50 \\
\hline Signnificancia & \multicolumn{6}{|c|}{$\mathrm{p} \leq 0,001$} \\
\hline
\end{tabular}

TABLA III

FRECUENCIA DE INFECGIONES DE TRANSMISIÓN SEXUAL (ITS) SEGÚN SU PRESENTACIÓN Y LA CONDICIÓN DE LIBERTAD EN MUJERES. MÉRIDA, VENEZUELA. 2018.

\begin{tabular}{|c|c|c|c|c|c|}
\hline \multirow[b]{2}{*}{ ITS } & \multicolumn{2}{|c|}{ Reclusas } & \multicolumn{2}{|c|}{ Libres } & \multirow[t]{2}{*}{ Significancia } \\
\hline & $\mathrm{N}$ & $\%$ & $\mathrm{~N}$ & $\%$ & \\
\hline Única & 17 & 61 & 10 & 100 & $\mathrm{P}<0,019$ \\
\hline Mixta & 11 & 39 & 0 & 0 & $\mathrm{P}<0,019$ \\
\hline Total & 28 & 100 & 10 & 100 & \\
\hline
\end{tabular}

Vol. 61(3): $227-241,2020$ 
jeres recluidas con un $35,7 \%(\mathrm{~N}=15)$, mientras que las mujeres libres presentaron una frecuencia de infección del 9,5\% $(\mathrm{N}=4)$, diferencia que resultó significativa $(\mathrm{p} \leq 0,004)$. $\mathrm{Al}$ discriminar las infecciones por un solo genotipo o múltiples genotipos de este aǵente viral, se obtuvo que solo las mujeres reclusas presentaron casos de infección por combinación de diferentes genotipos, lo que resultó ser estadísticamente significativo con respecto al grupo de mujeres libres $(\mathrm{p} \leq 0,011)$ (Tabla IV).

Chlamydia trachomatis se encontró en las mujeres reclusas con una frecuencia del $35,7 \%(\mathrm{~N}=15)$, similar al $\mathrm{VPH}$, mientras que en las mujeres libres la prevalencia fue menor con un $7,1 \%(\mathrm{~N}=3)$, esta diferencia fue estadísticamente significativa $(\mathrm{p} \leq 0,001)$; la infección por Treponema pallidum mostró una frecuencia de $7,1 \%(\mathrm{~N}=3)$ en el grupo de mujeres reclusas, mientras que en las mujeres libres no se encontró infección por este aǵente microbiológico. En cuanto a la detección de infección por el virus de la hepatitis B, las mujeres reclusas presentaron positividad al anticuerpo anti nuclear del virus (antiVHB core) en un 9,5\% (N=4), dicho marcador fue negativo para las mujeres en condición de libertad ( $\mathrm{p} \leq 0,040)$, el marcador anti antígeno de superficie (an-

TABLA IV

FRECUENCIA DE INFECGIÓN POR EL VIRUS DEL PAPILOMA HUMANO Y SU PRESENTACIÓN COMO INFECCIÓN ÚNICA O MÚLTIPLE Y LA CONDICIÓN DE LIBERTAD EN MUJERES. MÉRIDA, VENEZUELA. 2018.

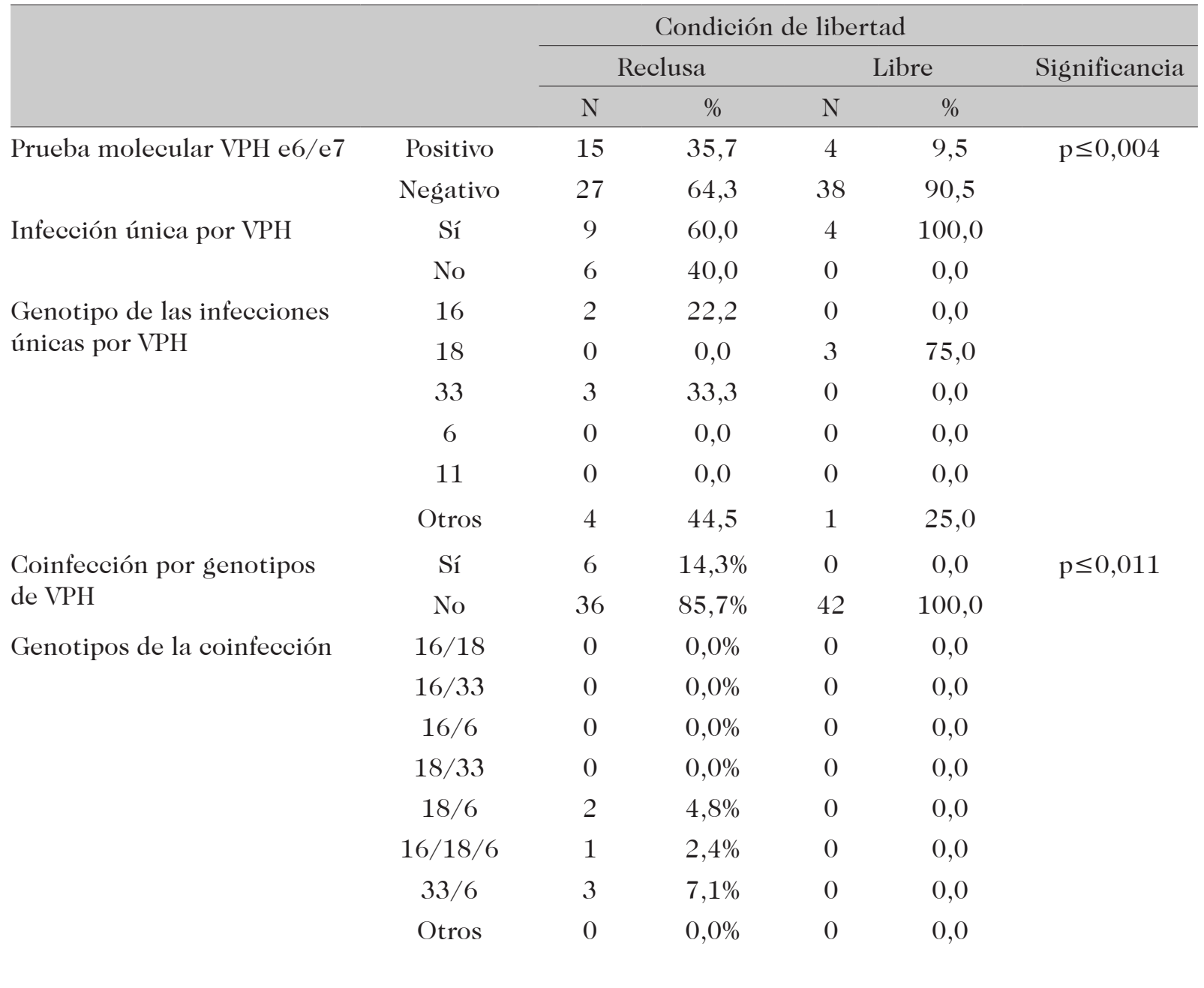


tiVHBs Aǵ Plus) resultó negativo en ambos grupos de mujeres, al igual que los mareadores serológicos para la detección de infección por el virus de la hepatitis $\mathrm{C}$ y el virus de la inmunodeficiencia humana (VIH). La detección de anticuerpos contra el virus del herpes simplex tipo 1 y 2 (VHS) se encontró en un $9,5 \%(\mathrm{~N}=4)$ de las mujeres reclusas y en el 7,1\% (N=3) de las mujeres libres, este hallazgo no mostró diferencias significativas entre ambos grupos (Tabla V).

En cuanto a las infecciones mixtas o coinfecciones encontradas en el grupo de mujeres reclusas, observadas en 11 de estas mujeres (39\%), se evidenció que la combinación de ITS más frecuente fue VPH/Chlamydia trachomatis $(27,2 \%)(\mathrm{N}=3)$, seguida por Chlamydia trachomatis /Treponema pa- llidum $(18,2 \%)(\mathrm{N}=2)$ y Chlamydia trachomatis/Virus herpes simplex $(18,2 \%)(\mathrm{N}=2)$, finalmente en frecuencias de $9,1 \%(\mathrm{~N}=1)$ se encontraron combinaciones entre $\mathrm{VPH} / \mathrm{Vi}$ rus hepatitis B, VPH/ Virus herpes simplex, Chlamydia trachomatis/Virus hepatitis B. Al considerar cada tipo de combinación encontrada por separado no se evidenció significancia estadística. Sin embargoo, al analizar las combinaciones encontradas entre los patógenos más frecuentes con otros agentes causantes de estas infecciones, se observaron diferencias significativas, en el caso de VPH con cualquiera de los otros microorganismos ( $\mathrm{p} \leq 0,007)$, y Chlamydia trachomatis en combinación con otro agente causante de ITS ( $\mathrm{p} \leq 0,003)$ (Tabla VI).

TABLA V

FRECUENCIA DE INFECCIONES DE TRANSMISIÓN SEXUAL SEGÚN AGENTE ETIOLÓGICO Y LA CONDICIÓN DE LIBERTAD EN MUJERES. MÉRIDA, VENEZUELA. 2018.

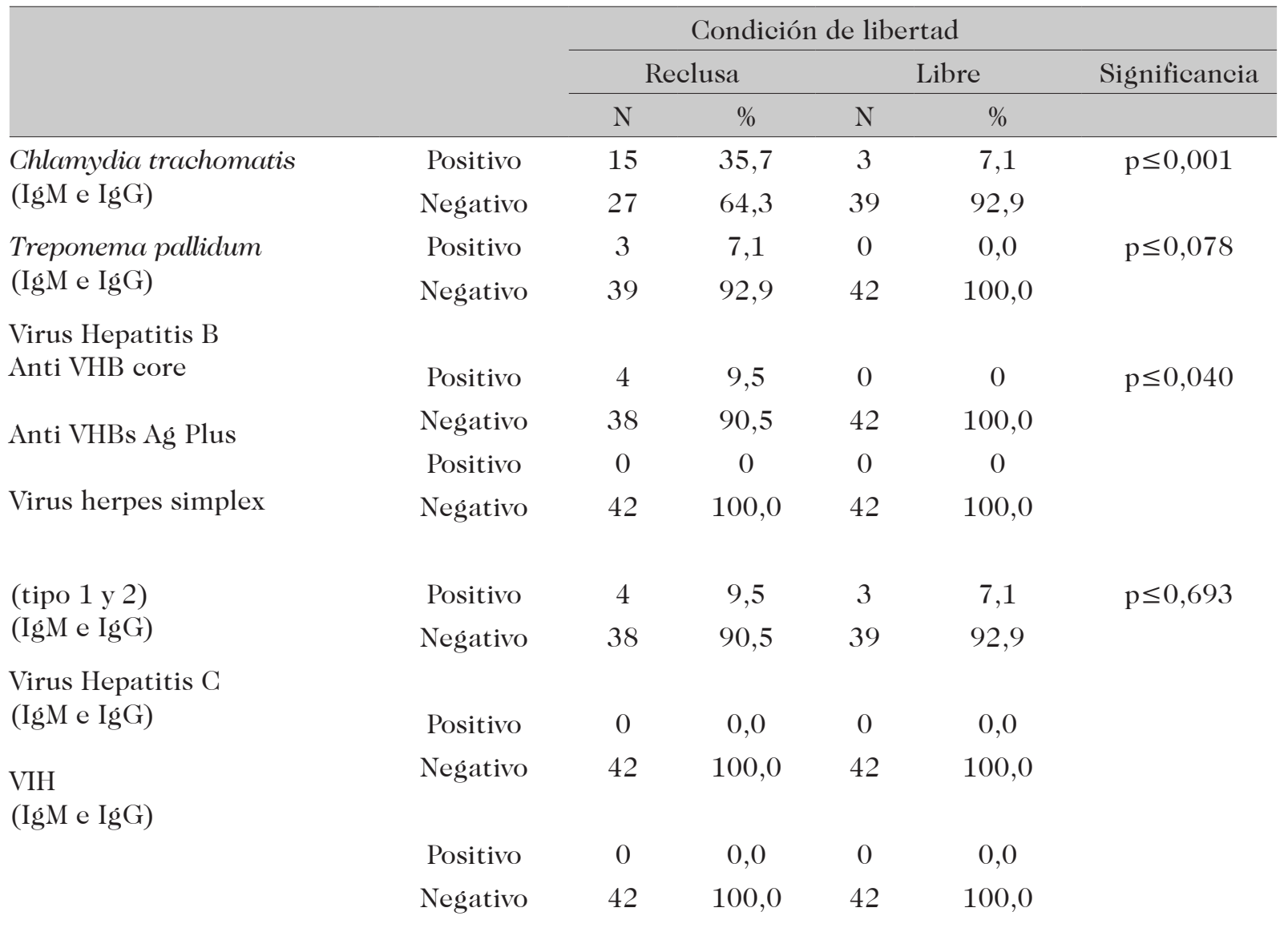

Vol. 61(3): $227-241,2020$ 


\section{TABLA VI}

FRECUENCIA DE COINFECGIONES DE TRANSMISIÓN SEXUAL EN MUJERES RECLUSAS. MÉRIDA, VENEZUELA. 2018.

\begin{tabular}{lccccccc}
\hline \multirow{2}{*}{ Coinfecciones } & \multicolumn{3}{c}{ Condición de libertad } & & \multirow{2}{*}{$\begin{array}{c}\text { Significancia } \\
\text { estadística }\end{array}$} \\
\cline { 2 - 5 } & \multicolumn{2}{c}{ Reclusas } & \multicolumn{2}{c}{ Libres } & & \\
\cline { 2 - 5 } VPH - C. trachomatis & $\mathrm{N}$ & $\%$ & $\mathrm{~N}$ & $\%$ & & \\
VPH - T. pallidum & 3 & $\mathbf{2 7 , 2}$ & 0 & 0 & $\mathrm{P} \leq 0,113$ & \\
VPH - VHB & 1 & 9,1 & 0 & 0 & $\mathrm{P} \leq 0,929$ & \\
VPH - VHS & 1 & 9,1 & 0 & 0 & $\mathrm{P} \leq 0,638$ & $\mathrm{p} \leq 0,007$ \\
C. trachomatis - T. pallidum & 1 & 9,1 & 0 & 0 & $\mathrm{P} \leq 0,638$ & \\
C. trachomatis - VHB & 2 & $\mathbf{1 8 , 2}$ & 0 & 0 & $\mathrm{P} \leq 0,246$ & \\
C. trachomatis - VHS & 1 & 9,1 & 0 & 0 & $\mathrm{P} \leq 0,638$ & $\mathrm{p} \leq 0,003$ \\
Total & 2 & $\mathbf{1 8 , 2}$ & 0 & 0 & $\mathrm{P} \leq 0,085$ & \\
\hline
\end{tabular}

En relación a los hábitos psicosociales reportados por mujeres con ITS se encontró, que el consumo de tabaco, alcohol y el uso de otras drogas, se observaron con frecuencias del $100 \%, 89,3 \%$ y $78,6 \%$ respectivamente en el grupo de mujeres reclusas, y en un $40 \%, 30 \%$ y $10 \%$ en las mujeres libres. Estas diferencias resultaron ser estadísticamente significativas $(\mathrm{p} \leq 0,001)$. El número de parejas sexuales se estratificó como se describe en la Tabla VII, las diferencias entre las frecuencias del número de parejas sexuales encontradas entre los dos grupos de mujeres y la presencia de ITS, resultó significativa para un número de parejas mayor de dos o parejas múltiples $(\mathrm{p}<0,006)$.

\section{DISCUSIÓN}

Mundialmente, la prevalencia de ITS e infecciones transmitidas por la sangre es mayor entre la población encarcelada que en la población general. Las reclusas que no reciben tratamiento en prisión pueden propagar su enfermedad. Así, por ejemplo, las mujeres privadas de libertad pueden contribuir proporcionalmente a la transmisión heterosexual y perinatal de las ITS $(10,13)$.

Algunos estudios realizados para detectar ITS en mujeres privadas de libertad han reportado una media de edad entre 34,1 años a 35,9 años $(10,14,15)$. Estos resultados son similares a los encontrados en esta investigación, donde el promedio de edad de las mujeres reclusas estudiadas fue de 31,9 \pm 9,4 años, destacando que de aquellas que resultaron positivas para la presencia de ITS, 64,2\% fueron $<35$ años de edad, y de estas $94,4 \%$ correspondieron a mujeres jóvenes $<$ de 30 años de edad.

En el presente trabajo, las prevalencias de ITS encontradas en mujeres reclusas fueron variables en relación al tipo de infección encontrada. Sin embargo, en todos los casos estas infecciones se encontraron en mayor prevalencia que en mujeres en condición de libertad provenientes de la comunidad, diferencia que resultó ser estadísticamente significativa. Se observó, que en el caso de la infección producida por Chlamydia trachomatis la prevalencia fue mayor que la reportada en estudios similares realizados en este tipo de población en diferentes partes del mundo como los descritos en Estados Unidos y en el Reino Unido (16-19). Chlamydia trachomatis se encontró en las mujeres reclusas con una frecuencia de $35,7 \%$, mientras que en las mujeres en condición de libertad fue de $7,1 \%(\mathrm{p} \leq 0,001)$.

En esta investigación la infección causada por VPH mostró una prevalencia similar a la de la Chlamydia trachomats $(35,7 \%)$; es 
TABLA VII

HÁBITOS PSICOSOCIALES EN MUJERES CON INFECGIONES DE TRANSMISIÓN SEXUAL Y SU RELACIÓN A LA CONDICIÓN DE LIBERTAD. MERIDA, VENEZUELA. 2018.

\begin{tabular}{lcccccc}
\hline & & \multicolumn{5}{c}{ Presencia de Infeceión } \\
\cline { 3 - 6 } & & \multicolumn{4}{c}{ Condición } & \multirow{2}{*}{$\begin{array}{c}\text { Siǵnificancia } \\
\text { estadística }\end{array}$} \\
\cline { 3 - 6 } & & \multicolumn{2}{c}{ Reclusa } & Libre & \\
\cline { 3 - 6 } Tabaco & Sí & 28 & 100,0 & 4 & 40,0 & $\mathrm{p}<0,001$ \\
& No & 0 & 0,0 & 6 & 60,0 & $\mathrm{p}<0,765$ \\
Alcohol & Sí & 25 & 89,3 & 3 & 30,0 & $\mathrm{p}<0,001$ \\
& No & 3 & 10,7 & 7 & 70,0 & $\mathrm{p}<0,765$ \\
Otras drogas & Sí & 22 & 78,6 & 1 & 10,0 & $\mathrm{p}<0,001$ \\
& No & 6 & 21,4 & 9 & 90,0 & $\mathrm{p}<0,765$ \\
Parejas sexuales & 1 & 4 & 14,3 & 8 & 80,0 & $\mathrm{p}<0,121$ \\
& $2-5$ & 19 & 67,9 & 2 & 20,0 & $\mathrm{p}<0,006$ \\
& $>5$ & 5 & 17,9 & 0 & 0,0 & - \\
\hline
\end{tabular}

de hacer notar que no en muchas instituciones de encarcelamiento se ha estudiado este agente viral debido a la dificultad y costos elevados de las pruebas diagnósticas específicas. El estudio de prevalencia de este virus, específicamente de genotipos de alto riesgo oncogénico en Alicante España realizado en 219 mujeres, reportó una frecuencia del $27,4 \%$ considerándose como una prevalencia elevada, los genotipos de VPH más comunes fueron VPH16 $(29,4 \%)$, VPH18 $(17,6 \%)$, VPH39 (17,6\%) y VPH68 (17,6\%) (20).

Otras investigaciones han descrito una prevalencia del VPH del 35\% en 114 mujeres de una prisión en la ciudad de Nueva York, del 16\% en 262 mujeres encarceladas en Sao Paulo Brasil y del 46\% de 157 mujeres en Barcelona España (20).

La prevalencia de VPH encontrada en este estudio, fue mayor a la descrita en Alicante España y en Sao Paulo Brasil, fue similar a la informada en Nueva York y menor que la reportada en una prisión de Barcelona España. Fue elevada de manera significativa en comparación a la frecuencia encontrada en las mujeres en condición de libertad incluidas en este trabajo $(\mathrm{p}<0,004)$.
Por otra parte, se encontraron infecciones mixtas por distintos genotipos de VPH en la población de mujeres reclusas, situación que no se presentó en las mujeres en condición de libertad. Este hallazgo pudiera significar que las mujeres en condición de cárcel están sometidas a factores de riesgo que pueden condicionar la infección con diferentes genotipos, como por ejemplo el tener actividad sexual con parejas múltiples; de igual forma esta combinación pudiera en algún momento condicionar el desarrollo de lesiones cervicales premalignas y malignas en estas mujeres de una manera más acelerada que en la población de mujeres no reclusas que cursan con infecciones por un único genotipo de VPH.

Treponema pallidum mostró una frecuencia de $7,1 \%$ en el grupo de mujeres reclusas, mientras que en las mujeres libres no se evidenció infección por este aǵente microbiológico, aunque esta diferencia no mostró significancia estadística entre ambos grupos. Esta ITS mostró frecuencias menores a la descrita en Asia (19,2\%) y Bolivia $(12,8 \%)$ y fue mayor a lo descrito en Irán $(10,14,21)$. 
En cuanto a la detección de infección por el virus de la hepatitis $\mathrm{B}$, las mujeres reclusas presentaron positividad al anticuerpo anti núcleo del virus (antiVHB core) en un 9,5\% ( $\mathrm{p} \leq 0,040)$; el marcador anti antígeno de superficie (anti VHBs Ag Plus) resultó negativo en ambos grupos de mujeres. La frecuencia encontrada en el presente estudio para este virus fue ligeramente mayor a la descrita en Asia, donde la prevalencia ponderada fue del $6,2 \%$, al igual que la descrita para las reclusas en Irán donde la prevalencia de los anticuerpos HBcAb, fueron del 7,4\%. Sin embargo, en Bolivia la prueba anti-HBc fue positiva en el 11,9\%, una prevalencia mayor a la encontrada en este trabajo $(10,14,21)$.

Los marcadores serológicos para la detección de infección por el virus de la hepatitis $\mathrm{C}, \mathrm{y}$ el virus de la inmunodeficiencia humana (VIH), resultaron negativos en el estudio realizado. Esta situación fue distinta a lo descrito en otras poblaciones de mujeres reclusas en diferentes países en los que se han descrito otras prevalencias de estos agentes infecciosos causantes de ITS (10, $14,17,18,21)$.

La detección de anticuerpos contra el virus del herpes simplex tipo 1 y 2 (VHS) se encontró en un 9,5\% de las mujeres reclusas estudiadas, y en el $7,1 \%$ de las mujeres libres; este hallazgo no mostró diferencias significativas entre ambos grupos. Las prevalencias resultaron ser más bajas en comparación con otras poblaciones de mujeres reclusas como en el estudio realizado en Bolivia, donde la seroprevalencias de VHS2 fue del 62,6\% (10).

Un hecho importante encontrado en este trabajo fue la presencia de coinfecciones con distintos agentes causantes de ITS en reclusas, no encontrándose en las mujeres en condición de libertad. Las combinaciones más frecuentemente encontradas fueron VPH/Chlamydia trachomatis, Chlamydia trachomatis/Treponema pallidum y Chlamydia trachomatis/VHS. A pesar de que estas asociaciones individualmente no mostraron significancia estadística, se observaron diferencias significativas, en el caso de VPH en combinación con cualquiera de los otros microorganismos $(\mathrm{p} \leq 0,007)$, y Chlamydia trachomatis en combinación con cualquier otro aǵente causante de ITS estudiados $(\mathrm{p} \leq$ $0,003)$. A este respecto se ha establecido que las ITS representan un cofactor importante para la progresión de lesiones cervicales asociadas a infección por VPH a grados severos (22). Se ha reportado que mujeres que cursan con infección por VPH en cuello uterino, suelen también ser positivas para infección por Chlamydia trachomatis, teniendo elevado riesǵo de desarrollar cáncer cervical $(23,24)$.

Esta combinación de agentes etiológicos causantes de infecciones transmitidas sexualmente en mujeres reclusas, refleja evidencia clara de que la actividad sexual de alto riesgo ocurre en entornos correccionales (11).

La violencia interpersonal (abuso infantil, violencia de pareja y violación) son problemas de salud pública importantes e interconectados que enfrentan las mujeres encarceladas (25).

Diversas investigaciones se han centrado en los factores de comportamiento que contribuyen al riesgo de ITS, como el uso del condón, el número de parejas sexuales y el uso de sustancias (13).

En este estudio se analizaron factores de comportamiento y hábitos psicosociales en mujeres con ITS reclusas y no reclusas. El hábito tabáquico, consumo de alcohol y otras drogas, y parejas sexuales múltiples, mostraron frecuencias elevadas en mujeres reclusas y estas fueron significativas estadísticamente con respecto a mujeres en condición de libertad. En cuanto al número de parejas sexuales $85 \%$ de las reclusas que presentaron ITS refirieron parejas múltiples, prevalencia más elevada que la descrita en cárceles de los Estados Unidos en donde un 16\% de mujeres reclusas tuvieron múltiples parejas en el último año (7). De igual modo, la prevalencia de múltiples parejas fue mayor que lo encontrado en mujeres encarceladas en Bolivia donde un 31,5\% refirió haber 
practicado relaciones sexuales durante su detención con parejas múltiples. Mientras que las reclusas en Brasil en un 53\% informaron relaciones sexuales múltiples con parejas ocasionales $(7,9,10)$.

Las prevalencias de consumo de alcohol y drogas en las mujeres reclusas de este trabajo fueron de $89,3 \%$ y $78,6 \%$ respectivamente, cifras que resultan muy elevadas en relación a reportes de los Estados Unidos en donde se han descrito prevalencias del $58 \%$ en mujeres encarceladas como consumidoras de heroína, cocaína u opiáceos, o de cárceles en Brasil en donde un 38\% de las mujeres han referido el uso de drogas. De igual modo, en el Reino Unido el consumo de drogas en cárceles se describe en un $41,2 \%$, específicamente el crack y en un $17,3 \%$ heroína $(7,9,16)$. Sin embargo, otros estudios realizados en Estados Unidos y Brasil describen prevalencias mayores y más cercanas a las encontradas en este trabajo; así se ha descrito un $85 \%$ de uso de sustancias en jóvenes encarcelados, y hasta un $68 \%$ de reclusas han informado síntomas de abuso o dependencia de drogas y alcohol, y un 84,7\% describe historial de participación en el uso de estas sustancias $(5,26)$.

Las mujeres con antecedentes de encarcelamiento que participan en el intercambio sexual (el intercambio de sexo por dinero, drogas $\mathrm{u}$ otros recursos) puede ponerlas en un riesgo superior al promedio en la adquisición y transmisión de ITS. El intercambio sexual puede conducir a numerosos resultados adversos para la salud durante la vida de una mujer encarcelada debido al riesgo acumulativo, ya sea en virtud de las prácticas asociadas de uso de drogas inyectables o debido a los encuentros sexuales de alto riesgo asociados con tales prácticas, por ejemplo, gran cantidad de parejas sexuales (27).

Es claro que las disparidades en la prevalencia de las ITS en mujeres encarceladas se deben a riesgos elevados, que incluyen el sexo sin protección, el uso de sustancias y las vulnerabilidades de salud mental. En un estudio entre reclusos recientemente libera- dos, las mujeres fueron significativamente más propensas que los hombres a reportar relaciones sexuales sin proteción $(44 \% \mathrm{mu}$ jeres vs. 21\% hombres, p <0,005) (28).

En Estados Unidos, en mujeres que ingresaron a prisión $(\mathrm{N}=207)$, se observó que un porcentaje elevado tuvieron múltiples parejas $(42 \%)$, parejas concurrentes (33\%) y sexo paǵado (11\%). La pobreza y la depresión parecían estar fuertemente asociadas con comportamientos de riesgo sexual; el uso de sustancias se relacionó con la ITS prevalente, y el consumo excesivo de alcohol fue el factor de riesgo independiente más fuerte (29).

Las mujeres involucradas en el sistema de justicia penal tienen más probabilidades de participar en comportamientos sexuales de alto riesgo y experimentar tasas más altas de ITS. Se recomienda que se ofrezca a todas las mujeres encarceladas programas integrales de tratamiento y prevención de ITS, y las mujeres encarceladas se hacen eco de esta necesidad. Se ha demostrado que los programas que enfatizan la educación sobre ITS, combinada con la capacitación de habilidades, la vivienda y el empleo disminuyen el comportamiento de riesgo para estas infecciones (30).

\section{REFERENCIAS}

1. Organización Mundial de la Salud. Infecciones de transmisión sexual. 2016; Consultado en: [En línea] 2016 [Citado el 18 de agosto del 2019] disponible en: http:// www.who.int/mediacentre/factsheets/ fs $110 / \mathrm{es} /$.

2. Garaycochea M, Pino R, Chávez I, Portilla J, Miraval M, Arguedas E, Linares P, Cabezudo E, Romero S, Espinoza M. Sexually transmitted infections in women living in a prison in Lima, Perú. Rev Peru Med Exp Salud Pública 2013; 30(3):423-427.

3. Organización Panamericana de la Salud. Guía de atención integral de las Enfermedades de Transmisión Sexual 2011. Consultado en: [En línea] 2011 [Citado el 18 de abril del 2019] disponible en: www. 
paho.org/ecu/index.php?option $=\mathrm{com}$ content\&view = article\&id=512:guia-atencion-integral-infecciones-transmision-sexual-2011\&Itemid $=9723$.

4. Huneeus A, Schilling A, Fernandez M. Prevalence of Chlamydia trachomatis, Neisseria gonorrhoeae, and Trichomonas vaginalis Infection in Chilean Adolescents and Young Adults. J Pediatr Adolesc Gynecol 2018;31(4):411-415.

5. Spaulding A, Miller J, Trigg B, Braverman P, Lincoln T, Reams P, Staples-Horne M, Sumbry A, Rice D, Satterwhite C. Screening for sexually transmitted diseases in short-term correctional institutions: summary of evidence reviewed for the 2010 Centers for Disease Control and Prevention Sexually Transmitted Diseases Treatment Guidelines. Sex Transm Dis 2013;40(9):679-684.

6. Satterwhite C, Newman D, Collins D, Torrone E. Chlamydia screening and positivity in juvenile detention centers, United States, 2009-2011. Women Health 2014;54(8):712-725.

7. Willers D, Peipert J, Allsworth J, Stein M, Rose J, Clarke J. Prevalence and predictors of sexually transmitted infection among newly incarcerated females. Sex Transm Dis 2008;35(1):68-72.

8. Steiner A, Haller D, Elger B, Sebo P, Gaspoz J, Wolff H. Chlamydia trachomatis infection in a Swiss prison: a cross sectional study. Swiss Med Wkly 2010;140:w13126.

9. Correa M, Croda J, Coimbra Motta de Castro A, Maria do Valle Leone de Oliveira S, Pompilio MA, Omizolo de Souza R, Ferreira de Sá Queiroz J, Esther da Silva K, Ko A, Simionatto S. Hiǵh prevalence of Treponema pallidum infection in Brazilian prisoners. Am J Trop Med Hyg 2017;97(4):1078-1084.

10. Villarroel M, Montaño K, Flores P, Jeannot E, Flores A, Cossio N, Valencia C, Salcedo A, Jiménez M, Castro R, Gétaz G, Bermúdez H, Wolff H, Gétaz L. Syphilis, human immunodeficiency virus, herpes genital and hepatitis B in a women's prison in Cochabamba, Bolivia: prevalence and risk factors. Rev Esp Sanid Penit 2018; 20: 47-54.

11. Hammett T. Sexually transmitted diseases and incarceration. Curr Opin Infect Dis 2009;22:77-81.
12. Sotlar K, Diemer D, Dethleffs A, Hack Y, Stubner A, Vollmer N, Menton S, Menton M, Dietz K, Wallwiener D, Kandolf R, Bültmann B. Detection and typing of human papillomavirus by e6 nested multiplex PCR. J Clin Microbiol 2004; 42(7):3176-3184.

13. Stoltey J, Li Y, Bernstein K, Philip S. Ecological analysis examining the association between census tract-level incarceration and reported Chlamydia incidence among female adolescents and young adults in San Francisco. Sex Transm Infect 2015;91(5):370-374.

14. Nokhodian Z, Yazdani M, Yaran M, Shoaei P, Mirian M, Ataei B, Babak A, Ataie M. Prevalence and risk factors of HIV, syphilis, hepatitis $\mathrm{B}$ and $\mathrm{C}$ among female prisoners in Isfahan, Iran. Hepat Mon 2012;12(7):442447.

15. Stein M, Caviness C, Anderson B. Incidence of Sexually transmitted infections among hazardously-drinking women following incarceration. Womens Health Issues 2012;22(1):e1-7.

16. Gabriel G, Burns T, Scott-Ram R, Adlington R, Bansi L. Prevalence of Chlamydia trachomatis and associated risk factors in women inmates admitted to a youth offenders institute in the UK. Int J STD AIDS 2008;19(1):26-29.

17. Fogel C, Gelaude D, Carry M, Herbst J, Parker S, Scheyette A, Neevel A. Context of risk for HIV and sexually transmitted infections among incarcerated women in the South: individual, interpersonal, and societal factors. Women Health 2014;54(8):694711.

18. Williams S, Bryant K. Sexually transmitted infection prevalence among homeless adults in the United States: A systematic literature review. Sex Transm Dis 2018;45(7):494-504.

19. Bernstein K, Chow J, Ruiz J, Schachter J, Horowitz E, Bunnell R, Bolan G. Chlamydia trachomatis and Neisseria gonorrhoeae infections among men and women entering California prisons. Am J Public Health 2006;96(10):1862-1886.

20. González C, Canals J, Ortiz M, Muñoz L, Torres M, García-Saiz A, Del Amo J. Prevalence and determinants of high-risk human papillomavirus (HPV) infection and cervi- 
cal cytological abnormalities in imprisoned women. Epidemiol Infect 2008;136(2):215221.

21. Azbel L, Polonsky M, Wegiman M, Shumskaya N, Kurmanalieva A, Asanov A, Wickersham J, Dvoriak S, Altice F. Intersecting epidemics of HIV, HCV, and syphilis among soon-to-be released prisoners in Kyrǵyzstan: Implications for prevention and treatment. Int J Drug Policy 2016;37:9-20.

22. Shew M, Fortenberry J, Tu W, Juliar B, Batteiger B, Qadadri B, Brown D. Association of condon use, sexual behaviors, and sexually transmitted infections with the duration of genital human human papillomavirus infection among adolescent women. Arch Pediatr Adolese Med 2006;160(2):151-156.

23. Samoff E, Koumans E, Markowitz L, Sternberg M, Sawyer M, Swan D, Papp J, Black C, Unger E. Association of Chlamydia trachomatis with persistence of high-risk types of human papillomavirus in a cohort of female adolescents. Am J Epidemiol 2005;162(7):668-675.

24. Zhu H, Shen $Z$, Luo H, Zhang $W$, Zhu $X$. Chlamydia trachomatis infection-associated risk of crvical cancer: A meta-analysis. Medicine (Baltimore). 2016;95(13):e3077.

25. Johnson J, Peabody M, Wechsberg W, Rosen R, Fernandes K, Zlotnick C. Feasibility of an HIV/STI risk-reduction program for incarcerated women who have experienced interpersonal violence. J Interpers Violence 2015;30(18):3244-3266.
26. da Silva E, de Souza A, de Souza T, Tsuha D, Barbieri A. Screening for cervical caneer in imprisoned women in Brazil. PLoS One 2017;12(12):e0187873.

27. Noska A, Roberts M, Sufrin C, Stein A, Beckwith C, Rich J, Dauria E, Clarke J. History of sex exchange in women with a history of incarceration. J Health Care Poor Underserved 2016;27(2A):149-162.

28. Kuo C, Rosen R, Zlotnick C, Wechsberg W, Peabody M, Johnson J. Sexual health prevention for incarcerated women: eroticizing safe sex during re-entry to the community. BMJ Sex Reprod Health 2018. pii:bmjsrh-2017-2024.

29. Khan M, Golin C, Friedman S, Scheidell J, Adimora A, Judon-Monk S, Hobbs M, Dockery G, Griffin S, Oza K, Myers D, Hu H, Medina KP, Wohl D. STI/HIV sexual risk behavior and prevalent STI among incarcerated African American men in committed intimate partnerships: the significance of poverty, mood disorders, and substance use. AIDS Behav 2015;19(8):1478-1490.

30. Knittel A, Ti A, Schear S, Comfort M. Evidence-based recommendations to improve reproductive healtheare for incarcerated women. Int J Prison Health 2017;13(34):200-206. 